\title{
Uma apreciação dos Ensaios sobre a Pintura de Diderot
}

\section{An appreciation of Diderot's Essays on Painting}

\author{
LUCIANO DA SILVA FAÇANHA ${ }^{1}$
}

MÁRIO BERTONY RIBEIRO COSTA ${ }^{2}$

\begin{abstract}
Resumo: Apresentar o filósofo Denis Diderot como o criador da disciplina Crítica de Arte em pleno século XVIII. As apreciações de Diderot se encontram em pleno desenvolvimento, mesmo que apenas de forma incipiente se verifique as características de uma crítica mais formal. A forma literária é um dos grandes achados do filósofo. Se as obras artísticas sempre foram objeto de juízos de valor, a justificação dessa nova função, a do crítico, corresponde a uma necessidade de reconhecer seu caráter, dentre outros, de mediador entre artistas e fruidores. Destarte, não há em Diderot, em seus Ensaios sobre a pintura, qualquer constrangimento acerca da possibilidade ou não de dissertar acerca das obras de seus contemporâneos ou suas credenciais para tal empreitada.
\end{abstract}

Palavras-chave: Arte. Pintura. Crítica. Diderot.

Abstract: Present the philosopher Denis Diderot as the creator of the subject art criticism in the middle of the 18th century. The assessments of Diderot are in full development, even if only so incipient that the features of a more formal review. The literary form is one of the great finds of the philosopher. If the artistic works have always been object of value judgments, the justification of this new function, the critic, corresponds to a need to recognize your character, among others, of mediator between artists and spectators. Thus, there is no in Diderot, in his essays on painting, any embarrassment about the possibility or not to speak about the works of his contemporaries or their credentials for such an endeavor. Keywords: Art. Painting. Critical. Diderot.

\section{Introdução}

\footnotetext{
${ }^{1}$ Pós-Doutorado em Filosofia, estética do Século XVIII - PUC/SP. Doutor e Mestre em Filosofia pela Pontifícia Universidade Católica de São Paulo. Bacharel em Direito pela Universidade Cidade de São Paulo e licenciado em Filosofia pela Universidade Federal do Maranhão. Atua na Universidade Federal do Maranhão (UFMA), como professor Adjunto no Departamento de Filosofia (DEFIL); Coordenador do Programa de Pós-graduação em Cultura e Sociedade - Mestrado Interdisciplinar (PPGCult); Professor nos Mestrados em Cultura e Sociedade e Mestrado Profissional em Filosofia da UFMA - PROF-Filo/UFMA. Foi coordenador do DINTER em Filosofia USP/UFMA; Coordena o NEPI Núcleo de Estudos do Pensamento Iluminista; é líder do Grupo de Estudo e Pesquisa Interdisciplinar Jean-Jacques Rousseau UFMA (GEPI Rousseau UFMA), registrado no Diretório dos Grupos de Pesquisa do CNPq. Integrante do Núcleo de sustentação do GT Rousseau e o Iluminismo da ANPOF (Associação Nacional de Pós-Graduação em Filosofia). Tem experiência na área de Filosofia, com ênfase no Pensamento do Século XVIII, atuando principalmente nos temas relacionados à estética do século XVIII, História da Filosofia Moderna, Iluminismo, problemas da linguagem na filosofia, História, Filosofia e Literatura, Belas-Letras e Belas-Artes. Se dedica aos estudos dos filósofos JeanJacques Rousseau, Diderot, Voltaire e Montesquieu e a teoria crítica literária contemporânea de Maurice Blanchot e Roland Barthes referentes aos estudos estéticos do XVIII. E-mail: lucianosfacanha@hotmail.com.

${ }^{2}$ Graduando em Filosofia pela Universidade Federal do Maranhão - UFMA. Bolsista de Iniciação científica do PIBIC/UFMA. Estudos em Fenomenologia, Existencialismo, Literatura argentina, estudos de gênero. E-mail: mario.bertony@hotmail.com.
} 
A filosofia permeia todos os escritos de Diderot. Na evidência tanto da riqueza de seus textos quanto da diversidade dos gêneros que praticou, estudiosos costumam definir essa postura através de metáforas ou qualificações do tipo "filósofo dos paradoxos", "cheio de máscaras" etc. Concluído em 1766 e publicado somente em 1795, postumamente, Os Ensaios sobre a Pintura de Diderot, é um exemplo a mais de como este autor criativo conseguiu ser inovador em áreas tão heterogêneas. Os Ensaios, que são, de certo modo, um arranjo mais maduro de sua experiência como crítico das exposições realizadas nos "Salões", são a expressão em forma de Tratado de seu próprio julgamento estético. Ligadas às academias de belas artes, os Salões eram grandes exposições que, em seu auge, tendo o filósofo como contemporâneo, tinham um enorme apelo popular. As circunstâncias em que foi escrito os Ensaios, perante o recente impedimento da publicação da Encyclopédie, o projeto grandioso do qual o filósofo era editor, e a terrível recepção de sua peça teatral $O$ pai de família, apenas incidentalmente podem ser utilizados como tentativa de explicação acerca da escolha de Diderot por uma disciplina nova, em sua época, como a crítica de arte (MATTOS, 2004, p. 191). A crítica de arte, por sua vez, não era ainda a disciplina qualificada e autônoma que na cultura moderna se apresenta em plena maturidade. "[...] a partir do século XVIII e da época do iluminismo que a literatura sobre a arte tomou a forma de disciplina crítica, desenvolvendo-se a diversos níveis: filosófico, literário, historiográfico, informativo, jornalístico, polêmico" (ARGAN, 1988, p. 127).

\section{Pintura e arte}

Sendo assim, não seria injusto para ambos, para disciplina ou filósofo, pensar em Diderot como um dos precursores da crítica de arte, definindo deste modo seu cânone, por um viés que lhe é próprio, tendo como fim a interpretação e avaliação das obras artísticas. Mas teria alternativa o Filósofo senão abordar da maneira mais digna o assunto a qual discorre? As apreciações de Diderot encontram-se em pleno desenvolvimento, pois mesmo que apenas de forma incipiente se verifique as características de uma crítica mais formal, rica em "terminologias apropriadas", a seriedade de seus juízos, tanto como a crítica definida de maneira simples pelo Dicionário de Língua Portuguesa Contemporânea, o identifica ao papel que "consiste em julgar, apreciar ou dar opiniões sobre o valor de trabalhos intelectuais ou artísticos" (2001, p. 1029). Função que ele enuncia com a prosa que lhe é característica:

Após descrever e julgar de quatrocentos a quinhentos quadros, terminemos por produzir os nossos títulos; devemos essa satisfação aos artistas que maltratamos, devemo-la às pessoas a quem essas folhas estão destinadas; expor francamente os motivos da confiança que se pode ter em nossos juízos talvez seja um meio de suavizar a crítica severa que fizemos de várias produções. Para este efeito ousaremos dar um pequeno Tratado de pintura e falar a nossa 
maneira e segundo a medida dos nossos conhecimentos do desenho, da cor, da maneira, do claro-escuro, da expressão e da composição. (DIDEROT apud MATTOS, 2001, p. 192).

A literatura permeia todos os gêneros de Diderot. A exposição, sem qualquer afetação ou adornos, de suas opiniões acerca da arte, extrairia delas muito da força das análises em que na sua prosa lhe é consubstancial. A forma literária é um dos grandes achados do filósofo. Se as obras artísticas sempre foram objeto de juízos de valor, a justificação dessa nova função, a do crítico, corresponde a uma necessidade de reconhecer seu caráter, dentre outros, de mediador entre artistas e fruidores. Mas não há em Diderot qualquer constrangimento acerca da possibilidade ou não de dissertar acerca das obras de seus contemporâneos ou suas credenciais para tal empreitada. Tanto que a forma que escolhe escrever seu Tratado é apenas suposta, pois a liberdade que instituiu em seus ensaios (ou cartas?) nunca demonstram a resignação envergonhada acusada em gêneros igualmente novos em sua época, como o romance (ROBERT, 2007, p. 12). "Apenas vós, meu amigo, lerás estes escritos; assim, posso escrever tudo o que desejar" (DIDEROT, 1993, p. 35).

Diderot inicia seu Ensaios sobre a pintura com frase tão categórica que sua importância para com o problema fundamental da obra se justifica: "A natureza não faz nada de incorreto" (1993, p. 31), diz ele. Há, dentre outras coisas, a constatação de que nada é por acaso na natureza, isto é, tudo que ela faz, "toda forma, bela ou feia, tem sua causa”, impedindo a possibilidade de tomar algo como sendo relativo ou "incorreto" quando este algo foi feito pela natureza. Este deverá ser inicialmente o parâmetro em que as "ideias bizarras sobre o desenho" de Diderot se baseiam, tendo como mote as relações entre arte e natureza.

Logo no início do primeiro ensaio, Diderot apresenta sua ideia de natureza, esta que nunca erra, como modelo para a criação artística. No entanto, devido às limitações inerentes ao homem e, neste caso, ao artista, como lhe está vedado a apreensão completa das causas e os efeitos, a relação entre ambas as partes se torna ambígua, entre o que está aí, na natureza, e o que o homem julga como belo ou feio. Esta constatação e esse problema é o que levará o filósofo a se contrapor aos métodos de ensino das academias e apresentar a natureza como modelo para a arte. A limitação natural em relação as leis da causalidade tornou imperioso a criação de métodos variados para suprir essa falta. Se essas leis "fossem evidentes, diz o filósofo, nada teríamos de melhor fazer do que representar os seres tal como são" (p. 32). Neste ponto ele supõe certa relatividade do belo artístico que a torna ora reprovável, quando o artista, iludido pela percepção daquilo que mesmo desproporcional não se lhe apresenta feio, tenta emular o efeito apenas permitido a natureza, e ora fértil, quando pautado por esta mesma natureza, segue regras próprias inspiradas nela. 
Um nariz torto, na natureza, de modo algum nos choca, pois tudo se ajusta; essas deformidades são produzidas por pequenas alterações adjacentes que as provocam e justificam. Entortai o nariz de Antinoos, deixando o resto tal como está, e este nariz ficará mal. Por que? É que Antinoos não terá um nariz torto, mas quebrado. (DIDEROT, 1993, p. 32-33).

Mas mesmo essas formas, ditas regras de convenção, não podem escapar da "tirania da natureza", pois mesmo elas, supostamente seguras na confiança de estarem seguindo um caminho imutável de medida e proporção, estão sujeitas as agruras do corpo e a "condição social", que moldam os seres vivos desde o nascimento, separando em intervalos de tempo, ou seja, entre início, meio e fim de uma vida, os momentos mais adequados ou não para serem expressos pelo artista. Não existe nem pode existir um ser, seja este um homem, que surja no auge de sua vida, seja a idade que for, entre a infância e a velhice, que não esteja sujeito a esses reveses. Na impossibilidade de "encontrar a figura de um homem de vinte e cinco anos, nascido subitamente do barro e que ainda nada fizera”, o que resta para o artista é representar considerando esses desgastes como a evidência de uma vida e se limitando, em sua arte, a conquistar um tanto de "pureza", "precisão", rigorosidade do traço etc, tão somente na representação deste homem entre os extremos da idade.

Assim, da importância necessária devida a idade, a função, as formas e ao que lhe são relativos, como os órgãos etc, é posto o valor do estudo anatômico. Mas este, por sua vez, não é considerado bom em sua totalidade. As restrições que Diderot lhe supõe está em que mesmo o estudo por modelos não sendo de todo mal, a originalidade da arte se baseia na observação direta da natureza:

O estudo do manequim anatômico tem, indubitavelmente, suas vantagens; mas não é o caso de se temer que este permaneça eternamente na imaginação; que o artista se torne obcecado pela vaidade de mostrar-se instruído, que seu olhar corrompido não consiga mais deter-se na superfície; que a despeito da pele e da gordura, ele entreveja seu músculo, sua proveniência, seu ligamento e sua inserção; que acentue tudo com demasiada veemência; que seja duro e ressequido e que eu reencontre até mesmo nas figuras de mulheres? Uma vez que deve mostrar-se apenas o exterior, preferiria que me acostumassem a vê-lo corretamente e que me acostumassem a vê-lo corretamente e me dispensassem de um conhecimento traiçoeiro que devo esquecer [...] Estuda-se o manequim anatômico, diz-se, apenas para aprender a olhar a natureza; mas a experiência mostra que depois desse estudo tornase muito difícil vê-la como ela é. (DIDEROT, 1993, p. 35).

O ensino tradicional, encarnado no estudo propagado pelas Academias, é desaconselhado pelo filósofo, que o identifica como a apreensão da maneira no desenho e na cor, considerado negativo pelo embotamento causado ao artista que se 
basearia em exemplos que não estão de acordo com a realidade. Podendo esta somente ser encontrada fora da escola, na busca do modelo cotidiano que está no mundo, em variadas figuras, no homem que é rico ou está passando fome, gozando de boa saúde ou não, na mesquinhez, na piedade, no sofrimento, no cansaço, no pensamento, etc, eis a verdade do modelo que difere do modelo da Academia, que de certo modo encena a forma e as adversidades pelas quais não passou, e que limitará o aluno à maneira, a "parte do objeto", à falsidade, ao invés de "fazê-lo observar os acidentes que as funções cotidianas, o modo de vida, a condição social e a idade introduziram nas formas" (DIDEROT, 1993, p. 39). Além da introdução da maneira como limitação, o autor também introduz primariamente a ideia do gênio, cuja "inspiração, a sensibilidade e o instinto refinado" se depuram dele mesmo e que precisa ser protegido das medidas que a escola, da maneira como é dirigida, tende apenas a inibir.

Esse processo é mais evidente em sua relação com a cor, onde o gênio exerce aquilo que para Diderot é um dom natural. O argumento decanta sua sutileza da contradição em que a cor, "que dá vida aos seres", é tão facilmente percebida em sua beleza quanto é difícil, no desenho, "que dá forma aos seres", o reconhecimento do mal feito. Mas "apenas os mestres na arte sabem julgar o desenho; qualquer um pode fazê-lo quanto a cor" (DIDEROT, 1993, p. 45). É que não há método para o colorista senão padecer sua sensibilidade, se isso fosse uma escolha, tanto que para o filósofo, a única alternativa para falar da cor e seu modo de usar é descrevendo como se comportaria um gênio. Nada seria menos infrutífero que tentar explicar isso didaticamente. Melhor seria um parodiar o autor, isto é, nesses quesitos, fazer entender qual o caminho usado pelo artista quanto a cor implicaria uma descrição tão apaixonada quanto a feita pelo filósofo, pois aquele que possui uma "viva sensibilidade para a cor" transcende, em seu fazer, qualquer poética ou arranjo daquilo que deveria seguir.

Um dos poucos traços da argumentação de Diderot referente ao fazer artístico em que ele se furta da crítica ao que chama de maneirismo acadêmico ou protocolo, como regras consagradas pelo artista, que por um lado o engessa e por outro distancia sua arte da natureza aparece em sua complacência a esse estudo que, mesmo estando relativo a regra ou método, ele não reprova: o aprendizado da perspectiva. A perspectiva é o caminho pelo qual o artista compreenderá o claroescuro.

O claro-escuro é a correta distribuição das sombras e da luz. Problemas simples e fácil, quando há apenas um objeto simétrico ou um ponto luminoso, mas cuja dificuldade aumenta proporcionalmente à variação de formas do objeto, à extensão da cena, ao número de seus seres, à multiplicidade de fontes de luz e a diversidade dos brilhos. Ah, meu amigo, quantas sombras e luzes falsas em uma composição de certa complexidade, quantos abusos, 
em quantos detalhes a verdade sacrificada ao efeito! (DIDEROT, 1993, p. 59).

Esta complacência apontada deverá, porém, estar ligada tanto mais a complexidade deste artifício na pintura do que da rara insegurança alegada pelo filósofo, baseado no que ele afirma ter podido entender sobre o assunto, tanto que delega ao tema do claro-escuro não apenas seu determinado capítulo como um acréscimo a título de "continuação" que serve como outro tópico. Aqui onde a mudança exerce sua autoridade, onde não há "uniformidade de luz", onde a realidade se baseia nas divergências de "sombras fortes, de sombras menos fortes, de partes obscuras, iluminadas, mal iluminadas, absolutamente resplandecentes", Diderot aconselha o estudo cadente da perspectiva.

Pintores, dedicai algum tempo ao estudo da perspectiva; sereis bem recompensados pela facilidade e segurança que através dela obtereis na pratica de vossa arte. Por um momento, meditai sobre ela e compreendeis que o corpo de um profeta envolto em toda a sua volumosa roupagem, tanto sua densa barba como seus cabelos eriçados sobre sua fronte e esse pano pitoresco que dá à sua cabeça um dom divino estão submetidos, em cada um de seus pontos, aos mesmos princípios do poliedro. Por fim, um não vos colocará em mais dificuldades do que o outro. Quanto mais multiplicardes o número ideal de vossos planos, mais exatos e verdadeiros sereis, e não receeis ser frios em virtude de um artificio a mais ou a menos acrescentado a vossa técnica (DIDEROT, 1993, p. 65).

Existe uma "finalidade nas artes", pela qual toda criação deverá se orientar, sendo esta preservar e valorizar seu sentido moral; este é um viés importante das argumentações que atravessará todo o quinto capítulo de Ensaios sobre a Pintura, onde Diderot analisa a questão da composição. Refere-se "artes" devido a abrangência de suas ideias, que não se restringem apenas as artes plásticas; mas já sua crítica ao academicismo englobava artes tão heterogêneas como a música, o teatro etc. Aqui a crítica é subliminar de uma vindicação daquilo a que se deve representar, para a finalidade de tal ou qual reação. A arte deverá ser sutil e perspícua. No pintor, tal exigência se torna imperativa, pois na omissão apropriada do excesso de imagens e na exposição do instante ela se torna "una, evidente, simples e coordenada", preservando a variedade mais grata da imitação direta da natureza.

Nossa perspicácia é limitada. Nossa capacidade de concentração somente se mantem durante certo tempo. Quando se faz um poema, um quadro, uma comédia, uma história, um romance, uma tragédia, uma obra destinada ao povo, não se devem imitar os autores de tratados de educação. De duas mil crianças, apenas duas poder-se-iam educar segundo seus princípios. Se tivessem pensado nisso, compreenderiam que uma águia não constitui o modelo comum de uma instituição geral. Uma composição que se pretende 
exibir a uma multidão de expectadores de toda espécie será inadequada se não pode ser compreendida por um homem de mero bom senso. (DIDEROT, 1993. p. 105).

"A composição pode ser pitoresca ou expressiva". Assim Diderot apresenta outra importante questão referente a composição, que inclui, perante juízos de valor, todas as características que o compõem (cor, luz, etc.), em conjunto, no que lhe é significativo. O prazer dos "órgãos", isto é, que agradam aos olhos, é alcançado com mais facilidade e é como que a medida pela qual se reconhece a composição pitoresca ou pintura de gênero, mas não restrito somente a ela. Enquanto na composição expressiva ou pintura histórica há, certamente, um objetivo mais moral e pedagógico, dirigida a alma do espectador. Mas essa relação não é estanque, podendo a composição expressiva ser, ao mesmo tempo, pitoresca, ao "imolar" seu conteúdo. Nada é inconteste em Diderot em se tratando do tema. O que é preciso é que haja expressão apaixonada e ordenação; que haja no quadro algo que nos "obsede" e nos "persiga", no sentido forte da comoção, da sensação. O cotidiano é o principal objeto do pintor de gênero; seu estilo é comedido, realista, rico em cenas rotineiras que o artista encontra sem dificuldades diante de si, como homens, mulheres, paisagens.

O pintor de gênero tem sempre sua cena diante de seus olhos; o pintor de história, ou nunca a viu ou apenas por um instante. E, de resto, um é pura e simplesmente imitador, copista de uma natureza comum; o outro é, por assim dizer, o criador de uma natureza ideal e poética. Ele caminha sobre uma linha difícil de ser mantida. De um lado desta linha, ele cai na banalidade; e do outro, no exagero. (DIDEROT, 1993, p. 117).

Diderot conjectura uma possível querela entre pintores históricos e pintores de gênero. Coincidentemente, e apenas de maneira subliminar, como feito pelo autor, pode-se associar esta questão a sua disputa pessoal em torno de seu projeto de educação, neste caso, através dos espetáculos teatrais, que ensinariam os homens a exaltar a virtude e a desaprovar do vício. No suposto desentendimento entre pintores históricos e pintores de gênero, estes são considerados "[...] espíritos estreitos, vazios de ideia, de poesia, de grandiosidade, de nobreza, de gênio, [...] são homens dedicados a assuntos triviais, a pequenas cenas domésticas apanhadas nas esquinas" (DIDEROT, 1993, p. 120). Enquanto o pintor de gênero condena no pintor histórico sua imaginação demasiada "romanesca", sua falta de verossimilhança e de verdade, onde o exagero e seu distanciamento da natureza são características da mentira. "Como bem podeis ver, meu amigo, é a querela entre a poesia e a prosa, entre a história e o poema épico, entre a tragédia heroica e a tragédia burguesa, entre a tragédia burguesa e a comédia ligeira” (DIDEROT, 1993, p. 122).

Acontece que para a cena francesa contemporânea ao filósofo, dominada pela tragédia e comedia clássicas, e sobrecarregada igualmente de regras e convenções, 
era duvidosa a capacidade, nesses moldes, de possibilitar qualquer educação. E a alternativa encontrada por Diderot para dotar essa nova dramaturgia de princípios que lhe permitissem o acesso a um potencial pedagógico é similar ao exposto nos Ensaios sobre a pintura, isto é, pelo reconhecimento da verdade na natureza, resgatando a "energia da linguagem, a energia da natureza de que a linguagem é portadora", e pela salvaguarda do novo teatro libertando a "cena" das regras e conveniências clássicas (MATTOS, 2009, p. 12). No caso das pinturas não há hierarquias relativas ao valor de cada uma, senão o esclarecimento das limitações expostas pelos dois queixosos que não se tornam menos que exemplos das dificuldades do fazer de cada um.

[...] a pintura de gênero apresenta quase todas as dificuldades da pintura histórica, que ela exige o mesmo tanto de talento, da imaginação, até mesmo de poesia, igual conhecimento do desenho, da perspectiva, da cor, das sombras, da luz, dos caracteres, das paixões, das expressões, dos drapejados, da composição; uma imitação mais fiel da natureza, uma grande atenção aos detalhes; e que, mostrando-nos as coisas mais conhecidas e mais familiares, seus juízes são mais numerosos e de superior qualidade. (DIDEROT, 1993, p. 122).

\section{Referências}

ARGAN, G. C. Arte e crítica de arte. Lisboa: Estampa, 1988.

DIDEROT, D. Ensaios sobre a pintura. Tradução Enid Abreu Dobránszky. Campinas, SP: Papirus, 1993.

MATTOS, F. de. "A querela do teatro no século XVIII: Voltaire, Diderot, Rousseau”. In: O que nos faz pensar, [S.1.], v. 18, n. 25, p. 7-22, aug. 2009. ISSN 0104-6675. Disponível em:

$<$ http://www.oquenosfazpensar.fil.puc-rio.br/index.php/oqnfp/article/view/271>. Acesso em: 28 de junho de 2017.

MATTOS, F. de. A cadeia secreta: Diderot e o romance filosófico. São Paulo: Cosac \& Naify, 2004 .

O filósofo e o comediante: ensaios sobre literatura e filosofia na Ilustração. Belo Horizonte: Ed. UFMG, 2001.

ROBERT, M. Romance das origens, origens do romance. Tradução de André Telles. São Paulo: Cosac Naify, 2007.

Submissão: 11. 02. 2018 / Aceite: 30. 03. 2018. 